\title{
Generic abstraction in design creativity: the case of Staatsgalerie by James Stirling
}

Fehmi Dogan, Faculty of Architecture, Izmir Institute of Technology, 35430 Urla, Izmir, TR, Turkey

Nancy J. Nersessian, School of Interactive Computing, Georgia Institute of Technology, Atlanta, GA 30332-0280, USA

This study examines the role of generic abstraction in architectural design, specifically how it facilitates exploration through formulation of a family of design schemes. We maintain that exploration in design, as it is in scientific discovery, is not solely based on serendipity, but that designers often strategically structure their explorations. We single out three instances of structuring through 'generic abstraction' in the case study of Staatsgalerie by Stirling. We hypothesize that generic abstractions help designers to mentally simulate different spatial components which lead to the generation of a novel design conceptualization. In the case at hand, the abstraction processes were sustained within a distributed cognitive system that consisted of one senior and two junior designers together with external representations in the form of sketches and diagrams.

(C) 2010 Elsevier Ltd. All rights reserved.

Keywords: creativity, diagrammatic reasoning, design cognition, distributed design, case study

Corresponding author. Fehmi Dogan fehmidogan@iyte. edu.tr

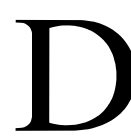
esign cognition studies emphasize the facilitating role of sketches in the process of creative discovery (Goel, 1995; Goldschmidt, 1991; Schön, 1992). Some of these accounts describe the design process via sketching almost exclusively either in terms of 'serendipity' (Suwa, Gero, $\&$ Purcell, 2000) or of 'piecemeal evolution' of design ideas through localized changes (Maher \& Tang, 2003). In the area of scientific discovery, although some researchers also point to the significance of serendipitous discovery in science (see, e.g., Thagard, 2002), numerous others show that creative ideas are often the outcomes of processes of reasoning through extended structured explorations (Darden, 1991; Giere, 1992; Gooding, 1990; Holmes, 1985; Nersessian, 2008). These explorations involve a variety of reasoning strategies, and here we focus on one we think particularly relevant to design. Nersessian $(1999,2008)$ has shown how a process of what she called 'reasoning via generic

www.elsevier.com/locate/destud 0142-694X \$ - see front matter Design Studies 31 (2010) 207-236 doi:10.1016/j.destud.2009.12.004

(c) 2010 Elsevier Ltd. All rights reserved. 
abstraction' was central to the scientific discoveries of both Maxwell and Faraday, and can be seen in the work of numerous other scientists. Generic abstraction consists of 'selectively suppressing information instantiated in a representation, so as to make inferences that pertain only to the generic case' (Nersessian, 2008, p. 193). In this paper we argue that reasoning via generic abstraction is also an exploration strategy that fosters creativity in architectural design.

We highlight the salient features of generic abstraction in a significant case study: James Stirling's Staatsgalerie Museum extension project using cognitive-historical analysis of archival records (Nersessian, 1992, 1995). Cognitive-historical analysis interprets and explains the generativity of reasoning practices in light of salient cognitive science investigations and findings of mundane cognition. Saliency is determined by the nature of the practices under scrutiny. The objective of cognitive-historical analysis is both to enrich historical interpretation and to enrich understanding of cognition in context through examining how these practices originate, develop, and are used in creative thinking. The practices can be examined over time spans of varying length, ranging from shorter spans defined by the activity itself to spans of decades or more.

Further, in the Stirling project, the abstraction processes were sustained through a collaborative effort within a distributed cognitive system (Hutchins, 1995) that consisted of one senior and two junior designers, and representations in the form of sketches and diagrams, and spanned the course of a five months. Lawson writes that 'until the untimely and tragic death of James Stirling, he and Michael Wilford shared a room, which in turn looked onto the general office through a large and normally open doorway. These two partners both worked on the same projects and hardly divided at all, even overhearing each other's telephone conversations and discussions with other staff' (Lawson, 2006, p. 249). Even though there are conflicting ideas about the extent to which Wilford was influential in the initial design phase of the projects, the particular setting in which Stirling positioned himself in the office tells us that he never was a loner as a designer and that he worked side-byside with others. As we have reconstructed, each designer in this distributed cognitive system had specific roles and each representational system had a corresponding cognitive function following the notion of coupled representational systems as suggested by Zhang and Norman (1994). Zhang and Norman studied problem solving in terms of specific cognitive roles of internal representations and external representations in a distributed cognitive system. Studying the effect of the use of different representational systems on problem solving, they found that external representations with different characteristics have significantly different facilitative roles in cognition. They claim that external representations activate the perceptual processes and internal representations activate the cognitive processes. In general, the totality of the research on diagrams supports the contention that diagrams, 
as form of external representations 'are not simply inputs or stimuli to the internal mind, rather they are so intrinsic to many cognitive tasks that they guide, constrain, and even determine cognitive behavior' (Zhang, 1997, p. 180).

As further argued by Nersessian (2008), there is ample evidence in the literature on diagrammatic reasoning that active perception of diagrams while reasoning provides situational information to working memory that interacts with mental models. The diagrammatic representation and the mental model "are best understood as "coupled," each providing their own constraints and affordances such that features of the external representations make direct contributions to transformations of mental models and vice versa' (p. 166).

\section{Generic abstraction}

The notion of generic abstraction in this study is adapted from the way it is used to explicate model-based reasoning in scientific discovery. Nersessian $(2002,2008)$ argues that there are several different kinds of abstractive processes used in reasoning with models, one of which is a form of reasoning that selectively suppresses information present in a specific representation, which she calls 'reasoning via generic abstraction.' The resulting abstraction 'represents features common to a class of phenomena' and is crucial in constructing a generic mental model (Nersessian, 2002, p. 129). For instance, she gives the example of a generic triangle. Although any drawing or image of a triangle is specific, in certain contexts the reasoner understands it to represent only those features that are common in all types of triangles (triangle-ingeneral). She argues that we construct such representations by re-making more detailed representations less and less specific so as to highlight only the most common features of a class of phenomena, or of ideas, or of design schemes in our case. A second example Nersessian (2002) gives is taken from Giere's (1988) analysis of how the linear oscillator is represented in textbooks, which she is understood by the physics community as a generic abstraction. She writes that 'in modeling a problem about a pendulum by means of a spring, the scientist understands the spring model as generic, that is, as representing the class of simple harmonic oscillators of which the pendulum is a member' (p. 129). A more detailed example is her analysis of Maxwell's discovery of electromagnetic induction and of the diagrammatic representations of the generic abstractions that helped Maxwell to derive the electromagnetic field equations. Building from representations developed by Faraday and by Thomson, Maxwell was able to derive the equations through constructing a series of models capturing the causal structure (generic) of electromagnetic field without knowing the specifics of the causal mechanism through which field actions are propagated.

In adapting the notion of generic abstraction to design processes, we propose that a representation is generic when it is understood to indicate the core of a design idea or the 'central idea' 'which structure[s] the scheme and around 
which other relatively minor considerations are organized' (Lawson, 1994, p. 139). Lawson indicates that such ideas are often called a 'concept' in architecture or 'parti' as well. Elsewhere, we called graphic representations of such ideas conceptual diagrams (Dogan \& Zimring, 2002). One could also interpret generic abstractions as a type and their specific variations as instances of the type.

What is powerful about generic abstraction as used in model-based reasoning is that it 'plays a highly significant role in the generation and integration of constraints, and in delimiting the scope of inferences' (Nersessian, 2008, p. 181). We propose that generic abstractions in design play a significant role in delimiting the scope of design explorations. Through such abstraction, the exploration is confined within the variations of a core idea. In this sense, a representation is generic because it potentially refers to a multiplicity of variations derived from the same core idea. Variations, which are instances, can in turn be compared and evaluated among each other and with respect to the core idea.

This contrast between generic and specific resonates with the distinction of form and design as proposed by Louis I. Kahn, who suggested that form is the generic idea and design is only one specific instantiation of that idea (Kahn, 1960). Kahn's conceptual diagram for his First Unitarian Church is an excellent example of a generic abstraction (Dogan \& Zimring, 2002). In this diagram, Kahn illustrated a concentric arrangement of spaces which induce both freedom of choice and unity within the building. Kahn drew this diagram at his first meeting with his client; therefore, we do not have information about how it was produced. The saliency of the Staatsgalerie case study, however, relies exactly on the fact that we have a well-documented design process that provides evidence for how such generic abstractions are drawn.

\section{Study of the design process}

The Staatsgalerie case study is based on an investigation of archival materials from the Stirling Collection at the Canadian Centre for Architecture and correspondence with the two junior members of the design team, Ulrich Schaad and Russell Bevington. The archival materials, approximately 505 graphical materials such as sketches and different types of drawings, plus textual materials such as correspondence and minutes from meetings, include all the available documents from the design process.

We classified and studied each of the graphical materials in the Archives according to its content and its format. The drawings that introduced new ideas and new design features were analyzed carefully for the author's annotations and diagrammatic abstractions. Sixteen sets of sketches from the conceptual design phase were reproduced as high resolution slides. The reproduced sketches were of crucial importance for tracking the evolution of the design 
ideas. Five additional sets of sketches from the early phases have been published in different journals. The published sketches together with the reproduced ones add up to 21 sets of sketches. Each of the 21 sets has a number of small and large sketches, which were examined for tracking the emergence and evolution of the design ideas.

In analyzing the drawings, we looked at the content and the format of each drawing together. In terms of content analysis, we were interested in understanding the themes considered, how much they were pursued in the process, and whether they were abandoned or not during the process. The analysis was carried out mainly through determining important architectural elements, such as the public path and the sculpture court in the case of Staatsgalerie, and their compositions, such as the particular combinations of the path and the court. The drawings were grouped and regrouped thematically to see to what extent a design element was explored. The thematic organization also helped us induce a rough timeline in the design process. Briefly, we could describe this part of our research process as an attempt to map the lateral and vertical transformations in the design as proposed by Goel (1995). The emergence of a new design element or different combinations of design elements could be considered as a lateral transformation. Each thematic organization in our analysis corresponds to such lateral transformations. With respect to vertical transformations, we grouped and counted all the variations of the same theme to see how and to what extent the theme is explored in the design process.

In format analysis, we looked at the medium with which the drawing was produced, such as the size and type of paper, the color and type of drawing instrument, and adherence to drawing conventions, such as scale, type of lines, and type of drawings. In doing so, we were particularly interested in differentiating those drawings which were drawn with different colors and with different line types, knowing that differences in color and type indicated a different designer, either a senior or a junior designer. We suggest that at those times when we could identify the drawings of the senior designer, it is more likely to see a lateral transformation in the design.

In our study, the main difficulty in the analysis of the drawings related to the temporal sequencing of the drawings. Almost none of the drawings studied had a date on it, which required us to establish a tentative timeline in light of the content and format analysis of the drawings as well as additional data that we collected through archival sources and other sources including the surviving members of the design team. Furthermore, mapping an exact timeline was not necessary for this particular study even though such a timeline would have helped in understanding the minute changes in the design process. We were, rather, mostly interested in highlighting the major shifts in the design process which could be identified given that one has an almost complete set of 
alternatives considered by a team of designers. The boundaries of the exploration could be traced by investigating the full set and the different branches of alternative schemes could be tracked back to few initial schemes.

There are few textual materials available at the Archives and these are of secondary importance. However, they were helpful in consolidating the timeline of the design process and its aftermath.

In addition to the archival documents, published material about the significance of the Staatsgalerie provides substantial amount of information about the design situation and the impact of the building on architectural theory and practice of its time (Baker, 1992; Colquhoun, 1984; Muirhead, 1986; Pélissier \& Stirling, 1986; Stirling, 1980; Werner, 1984; Wild, 1977). Among the published studies, Lawson (1994) is important for our study with respect to understanding the conditions of collaboration in the office of Stirling and Wilford. Goldschmidt and Klevitsky's (2004) and Fraser and Henmi's (1994) works on Stirling are especially informative in understanding the use of drawings, especially axonometric drawings, in Stirling's office. Lawson, in describing Michael Wilford's architectural practice from Stirling and Wilford Associates, detailed how the work was carried out in the office of Stirling and Wilford. There, Lawson recounted the general design principles and approaches in the office of Stirling and Wilford.

Goldschmidt and Klevitsky (2004) and Fraser and Henmi (1994), specifically dealt with drawings of Stirling and Wilford Associates. These authors, however, focused mainly on the use of axonometric drawings in Stirling's office and how bird-eye and worm-eye view axonometric drawings were influential in different periods of the office career in emphasizing certain aspects of their projects. Goldschmidt and Klevitsky have called some of these axonometric drawings 'conceptual drawings.' These are abstract and do not represent the physical properties of the end product. They claim that such drawings were to represent 'the essentials (and only the essentials) of the relationship between form, space and movement' (p. 44). In the drawings which we analyzed for this case study, there are many such axonometric drawings that accompany section and plan drawings and diagrams. One could see that all these drawings are relatively very simple and abstract drawings. For the purpose of this study, however, we concentrated mainly on those abstract drawings which are diagrams that lay out the essential in plan organization.

Goldschmidt and Klevitsky's (2004) article put the Staatsgalerie in context together with two other museum competition projects that Stirling's office entered prior to Staatsgalerie, namely the Düsseldorf and Cologne Museum competitions. The office did not win these competitions; however, their projects bear some of the elements and issues that would be revisited in the Staatsgalerie project. The reader is referred to Goldschmidt and Klevitsky's article 
for a detailed account of the context of the Staatsgalerie project. Briefly, the authors show how the idea of circulation, which they claim is one of the main generating ideas in Stirling's projects, was articulated in the three museum projects, which were very conducive to a study of circulation as a central design issue. According to the authors, Stirling was concerned with laying out a narrative in and out of the building through circulation paths and used worm-eye axonometric drawings especially to illustrate this narrative. In the drawings that we analyzed, this concern for circulation as one of the main generating issues of design is discernible in the articulation of the public path as well.

The building, when it was finished and opened to the public, was so successful that it was widely published in the architectural journals and stimulated discussions about monumentality, symbolism, and historicism. The published material contained additional information about the important issues addressed in the competition brief and by the design team.

The writings of Stirling and Wilford on the work dynamics of their office, their philosophy of design, and their way of working with different architectural representations provided a second body of important documentation for our analysis. Neither Stirling nor Wilford were theoreticians, and their writings are concise, yet to the point. Wilford's writings are especially significant because after Stirling's sudden death, the architectural media had consulted Wilford to explain in detail what Stirling, Wilford and Associates' architecture was about.

The final body of evidence we used were the reports of Schaad and Bevington, the surviving members of the design team. Schaad and Bevington made significant contributions to the design. They are currently practicing architects, the former in Switzerland and the latter in the UK. They answered our questionnaire consisting of 27 questions about the design process (see Appendix). Their responses were of crucial importance in determining the nature of the collaboration among them and in authenticating the set of sketches. The questions were sent to Bevington and Schaad separately. They did not see each other's answers until both answered the questions and sent their answers back to the authors. The questions inquired about several issues ranging from the temporal sequencing of events and design decisions, to the nature of collaboration and communication in the office, to the type of drawings used, to authorship and role of particular drawings, and finally to the significance of the path and the court for the design of the Staatsgalerie. Responses to most of the questions corroborated with each other. A few exceptions were questions related to time, which were resolved through consulting archival material such as airplane tickets to Stuttgart. A few more important conflicting responses related to the beginning of the design process and to the importance given to some of 
the design elements. These were resolved again either through consulting drawings and documents from the archive or sources from the literature.

Given the nature and multiplicity of the data collection techniques that we used in this study it was inevitable that some data from some different sources would lead to conflicting conclusions. Whenever available the archival data, especially data from the drawings, were considered as primary and were used to resolve the conflicting issues. Where conflicts remained unresolved we did not include them in the reconstruction of the case study.

\section{Design issues}

In April 1977, the state of Baden-Württemberg, Germany, announced an invited competition for the extension of the Staatsgalerie and the redevelopment of its close vicinity in Stuttgart. This was an international and restricted competition to which only eleven architectural offices were invited, Stirling and Wilford's office being one of them.

The competition brief emphasized the urgency of restoring the spatial and historical continuity of the urban fabric by enhancing pedestrian movement. The program included three components: (1) an expansion to the Staatsgalerie, (2) a new theater building, and (3) a Music school building. Furthermore, the competition brief given to the architectural offices addressed some specific issues and made some explicit suggestions about how the urban character of this area could be restored. The central issue addressed in the competition was the restoration of the integrity and continuity of the area, whereas the specific requirements of the competition brief were as follows (Filler, 1984):

- Pedestrian path: A pedestrian path across the site should create a link between the residential neighborhood behind the Staatsgalerie and the more civic district in front of the Museum.

- Historical continuity: The new building should contribute to the historical significance of the area by way of establishing relationships with other historical buildings around the site.

- Highway: The new design should improve the discontinuity caused by the harsh presence of a major highway, the Konrad Adenauer Strasse, on the west of the building.

- Scale: The new building should respect the small scale of buildings on the site.

- Terrace: A 10-foot-high terrace is suggested along the main façade of the building for the passage of pedestrians via a bridge to be built over Eugenstrasse to connect the site with the areas in the south of the building.

- Parts and whole: The unity of the overall composition and the excellence of the constituting parts should be of equal importance.

- The gallery spaces: The exhibition spaces should be in a sequence of well-defined and well-proportioned rooms. 
In response, the design team configured a scheme that would accommodate the public circulation through the building without disrupting the integrity and wholeness of the Museum, while allowing the public a close experience of the activities in the Museum. Schaad summarizes this point as follows:

'A public footway connection from Adenauer Strasse to Urbanstrasse across the site was a requirement in the brief. Its formal weaving into the design was just part of the job. We wanted to give the public a chance to walk through the sculpture terrace or court. It was quite difficult to design a path, which would bring the casual passer-by in contact with the outdoor sculpture exhibition yet prevent direct access for security reasons, and segregate from the paying museum-visitor.' (Personal correspondence with Ulrich Schaad, October 31, 2002. All references to Schaad are to this correspondence unless otherwise noted.)

Bevington, however, suggests that the requirement for a 'footpath' was set aside until the building was resolved and the path was added later. (Personal correspondence with Russel Bevington, November 21, 2002. All references to Bevington are to this correspondence unless otherwise noted). Given that there were no schemes without a path in the original drawings we analyzed, it is very likely that Bevington's account is not complete.

\section{Design process}

Starting the project, the competition brief was translated from German to English by Schaad who was the first to start working on the design (Schaad). Schaad remembers that the first time he went to Stuttgart was sometime during the Fall 1977, after the competition results were announced. However, in the Architectural Archives of the Canadian Centre for Architecture (hereafter abbreviated as the Stirling Archives) there is a roundtrip airplane ticket between London and Stuttgart issued on the name of Schaad for the date of March 28, 1977. It is likely that he went and received the brief for the competition as well as visited the site. Stirling asked Schaad to start thinking about the project before leaving for Yale University for a brief period. Schaad reports that he translated the brief from German to English, even though Bevington claims that the brief was in English already, and started working first, Bevington joining him later. Girouard (1998) reports that Stirling left for Yale right after they received the competition brief. Stirling taught at Yale during the Fall semester as the Davenport Professor of Architecture. During the Spring Semester of 1977, however, he only visited Yale briefly for a series of seminars (personal communication with Grazyna Kirsch, Registrar and Admissions Administrator School of Architecture, Yale University, October 30 , 2002). He was not away from the office for a long time and became involved in the design as soon as he got back from the States. This evidence appears contrary to Girouard's report which suggests that Stirling was away for longer and that during his absence the scheme was almost resolved and complete. 
As a starting point, the assistants identified two precedents as sources of ideas: their previous museum competition project for Düsseldorf, the Kunstsammlung Nordrhein-Westfalen, shown in Figure 7a (Rodiek \& Stirling, 1984; Stirling, 1984), and the historical Temple of Fortuna, shown in Figure 1 (Schaad). Schaad mentions that the first precedent which came to his mind was Temple of Fortuna at Praeneste. He explains that this particular building served as a model for the Staatsgalerie project and 'the Düsseldorf project also made its way into Stuttgart' (Schaad). Bevington does not mention the Temple of Fortuna, however, he recounts that Stirling left for Yale leaving him and Schaad 'to start work with the thought that it [Staatsgalerie] should be a "Düsseldorf Mark 2"” (Bevington).

In both the Kunstsammlung and the Staatsgalerie projects, a pedestrian path and a circular courtyard are the most significant elements of the design. Inspired by the Temple of Fortuna, the architects for the Staatsgalerie layered the building on a series of terraces and used ramps to connect the different levels. The transferred elements from the two precedents, i.e., terraces, ramps,

Figure 1 Temple of Fortuna at Praeneste

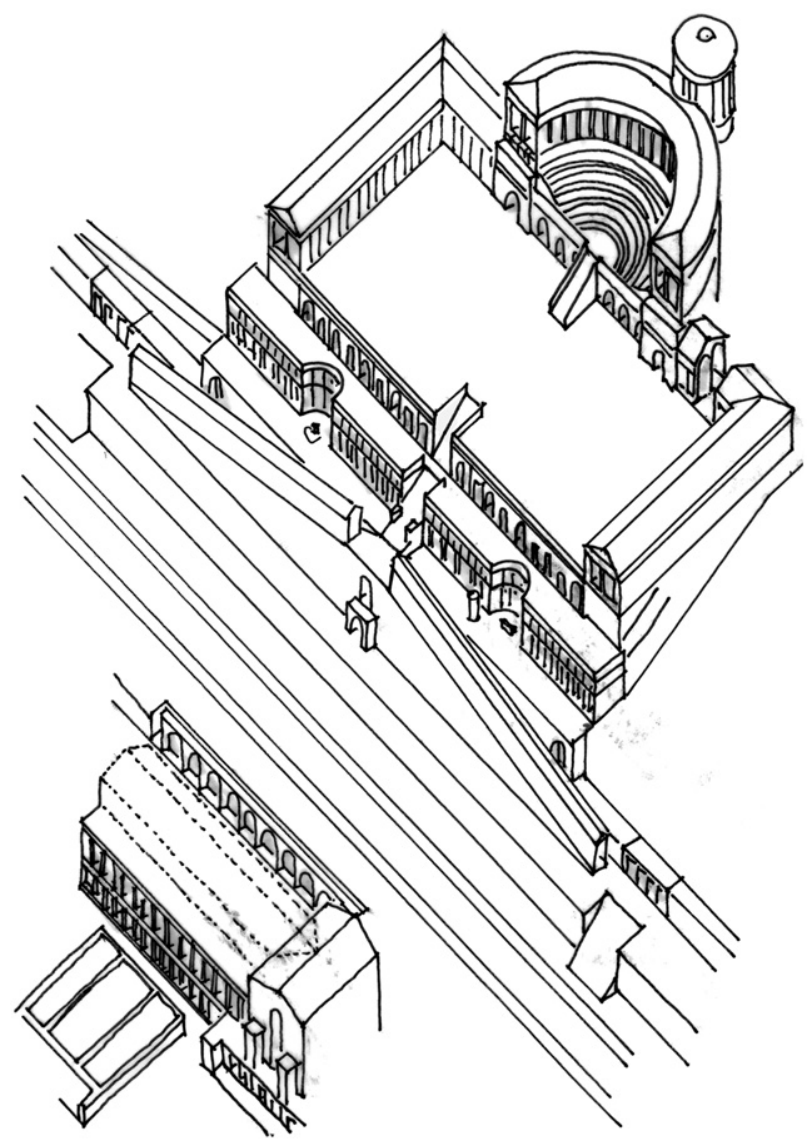

Design Studies Vol 31 No. 3 May 2010 
public path, and a central court, began as and remained significant design elements throughout the design process.

Some scholars claim that the Altes Museum designed by the 19th century German architect Schinkel was of crucial importance for the Staatsgalerie design project (Blundell-Jones, 1985; Girouard, 1998; Lemos, 1985; Waterfield, 1987). In some of his articles on Staatsgalerie Stirling also mentioned the importance of Schinkel's museum for his scheme (Stirling \& Wilford, 1984, p. 5). However, the sketches and other documents at the Stirling Archives do not provide any evidence to support this claim. In the Stirling Archives, there is only one item that points to a possible connection with the Altes Museum. This consists of a pair of renderings on a sketch paper with two slides taped underneath showing respectively the elevation and plan views of Altes $\mathrm{Mu}-$ seum. The sketch, however, is quite vague and there is nothing to indicate that it played any role during the design process.

After Stirling came back from the States he became involved in the design process and collaborated closely with Schaad and Bevington. Stirling might have visited Stuttgart during this period, though this not conclusive. Schaad reports that nobody from the office visited the site during the competition phase, yet, the Stirling Archives has a roundtrip ticket between London and Stuttgart issued on the name of James Stirling for May 17-18, 1977. The Staatsgalerie design process lasted for five months, with August 30, 1977 as the deadline for the submissions. The final drawings for the Stirling and Wilford entry were ready in August and an architectural model weighting about $87 \mathrm{~kg}$ was sent to Stuttgart on the 31 st of August via airmail, which is documented by an air express receipt slip for an architectural model from Stirling to Mr. Bulrlon Stuall Hochbaulum.

After the initial phase, the design proceeded through two coordinated explorations. First, the junior designers produced a vast number of variations. Second, the senior designer, Stirling, took these variations and abstracted generic schemes with the idea of incorporating a public path going through the building with a central court, as drawn in the final competition submission. In the remainder of this paper we examine the nature of these explorations and how creativity was fostered by means of them.

The path, the first important theme of the design, was worked out in numerous sketches. There are no schemes without some sort of a path crossing the building. The shape and configuration of this path, though, changed throughout the exploration. The team considered two categories of variations of the idea of path: paths with no turns and paths with turns (Table 1). The primary example of the first is the straight path scheme (22 instances). The example for the second is a zigzag path where the public circulation makes several turns through the building (14 instances). There are two further variations of each of these 
Table 1 Different variations of the path element. The schemes are categorized according to whether they have any turns and whether they provide an opportunity for pause for pedestrians passing through the building or not

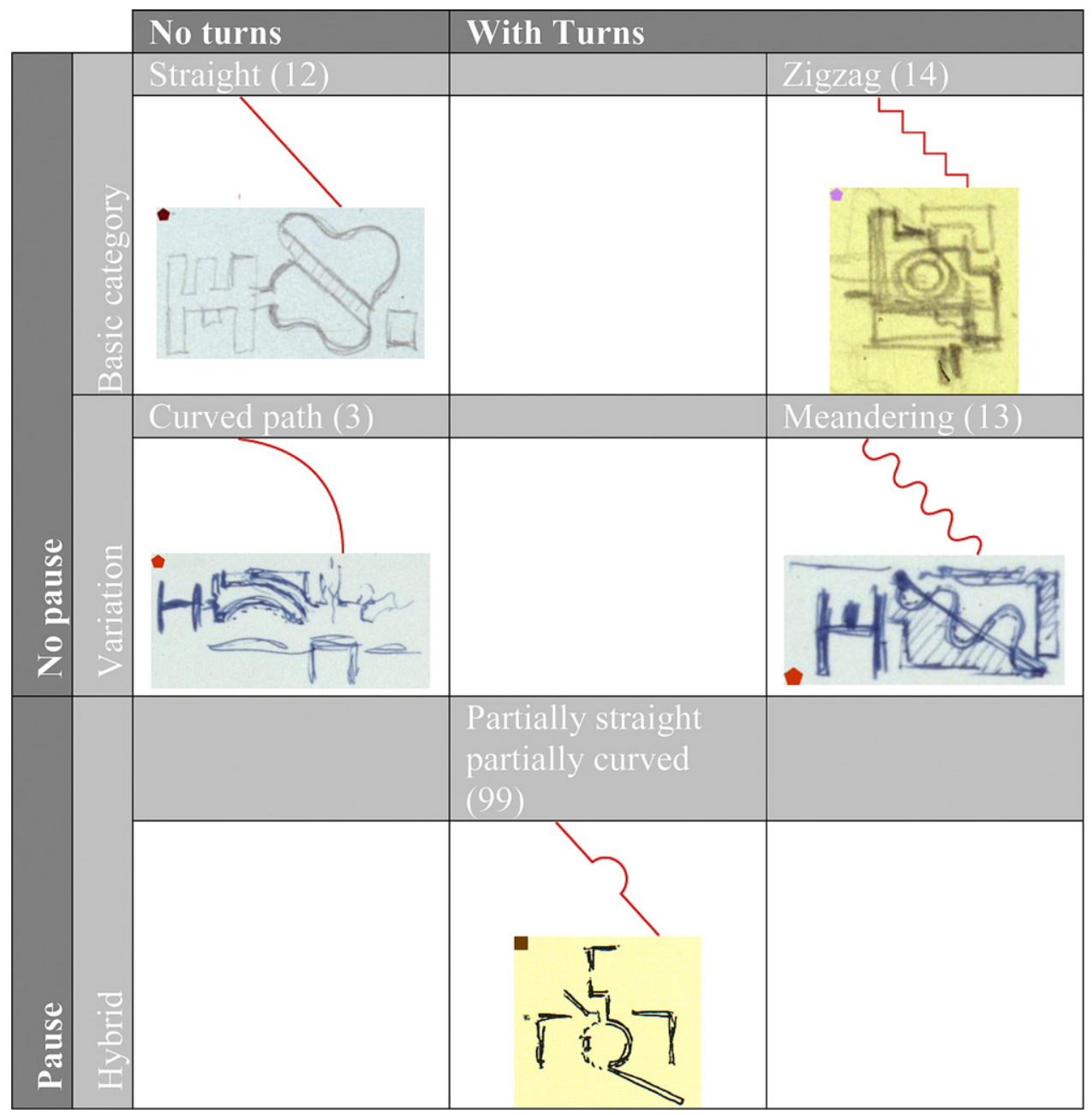

categories. The large curved path ( 3 instances) is a variation of the scheme with no turns, whereas the meandering path (13 instances) is a variation on the zigzag path scheme. The final category comprises hybrid schemes of straight paths and paths with turns (99 instances). An example of this category is a path that enters the site directly, makes half a circle around the sculpture courtyard, and then proceeds directly to the outside of the site. Generally, the team tried to achieve a scheme where the public would use the path as a shortcut and still enjoy the building as much as possible. In the hybrid schemes, the time spent is elongated and the general public is given a chance of a momentary pause to experience the sculpture court. 
The second important theme in the design was the idea of a centrally located sculpture court that would unify the fragmented components (Figure 2). The court emerged early in the design process, most likely in reference to the Düsseldorf competition entry. There were only 13 schemes without a court as opposed to 228 schemes with a court among all the sketches investigated in detail. Once it emerged, the shape of the court was studied in several variations, which can be grouped in six headings according to shape: triangle ( 2 instances), rectangle (11), square (13), ellipse (6), circle (195), and semi-circle (1).

The team considered numerous schemes. Neither the path nor the court, however, was studied independently. The trajectory of the path determined the shape of the court and the shape of the court determined the configuration of the path (Figure 3). In terms of the configuration of the path and court, there are five categories, with their respective numbers of occurrence: path without a court (19 instances), path without connection to court (17), path tangent to the court (10), path intersecting the court (24), path around the court (95).

In those schemes without a court, the path dissects the building into disconnected fragments. In the schemes with a court, the court is a central focal
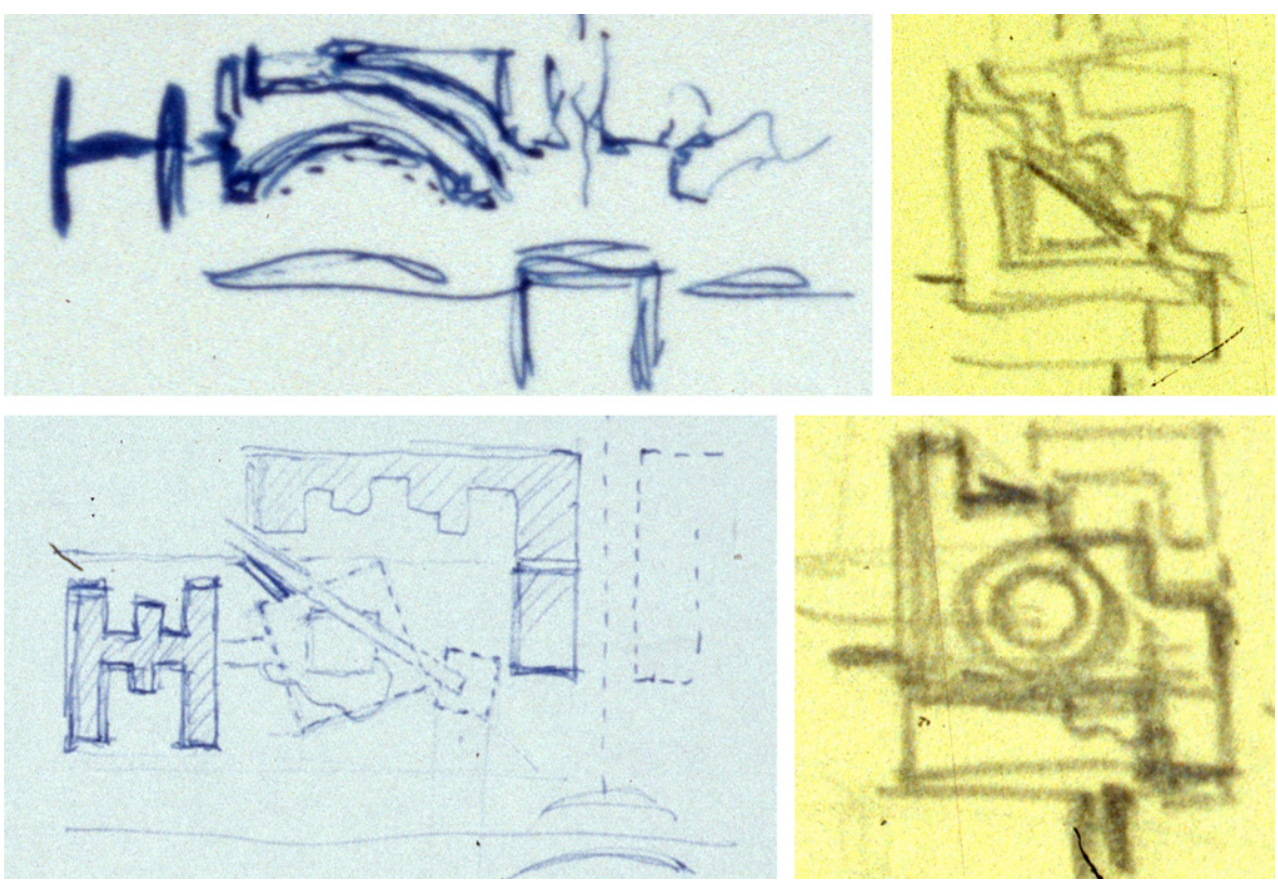

Figure 2 Four schemes showing four different configurations of the court. The first illustrates a scheme without a court, the second with a triangular court, the third with a square one, and forth with a circular one. (All the drawings are from @) James Stirling/Michael Wilford Archive, Centre Canadien d'Architecture/Canadian Centre for Architecture, Montréal unless otherwise specified. Reprinted with permission) 


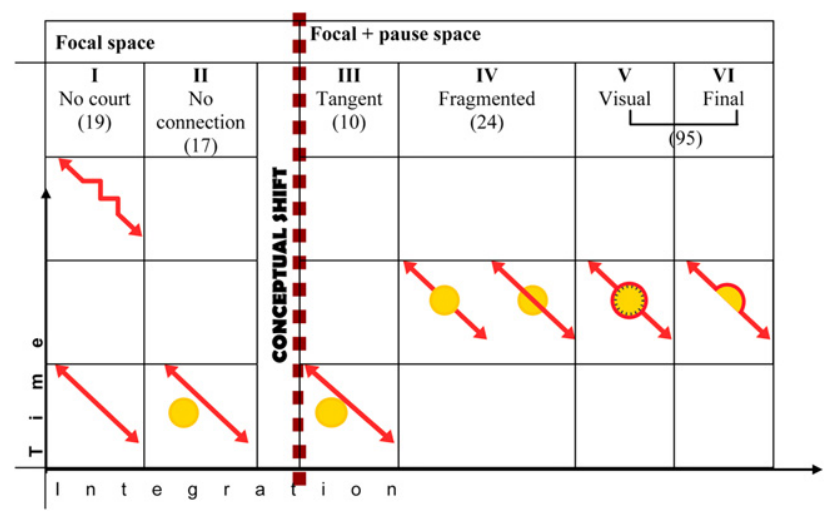

Figure 3 The graph above shows a categorization of path/court configurations according to their integration and the time it takes to cross the building with the last column showing the final solution. ' $\mathrm{Y}$ ' axis shows the time they anticipated would be spent in the building while the ' $X$ ' axis shows integration between the path and the court. The dashed line in the middle indicates the shift in the conception of the court idea

element. When the court is fragmented into two by a dissecting path or is tangent to the path, the overall building remains somewhat fragmented also. When the path enters the courtyard diagonally, it is either the path or the court which is dissected and their continuities disrupted.

Finally, in schemes where the path wraps around the court, there is a compromise. Neither the path nor the court is fragmented. The path retains its integrity while providing enough exposure to the museum. When the section sketches and the axonometric drawings are studied, we see two subcategories of this variation, of which one is the final scheme. In the first sub-category the path wraps around the courtyard yet it stays at a higher level, i.e., the path never reaches down to the courtyard floor (Figure 4). In the final scheme, the path proceeds downward to the floor of the court along the curvilinear wall of the courtyard (Figure 5). It is this scheme the team entered into the design competition. In its new configuration, the court became a place of pause for pedestrians, including non-museum goers living in the neighborhood (Figure 6). This suggests a shift in the conception of the court from being solely a central place for the building to becoming a center of focus for both museum visitors and the residents of the neighborhood using the path.

All the important shifts during the design process, including the emergence of the idea of court, appear to have occurred through processes of abstraction performed by the leading designer, namely Stirling. In these abstractions, Stirling first conceived the path and court in terms of their basics, then established a meaningful connection between them, and finally, modified their meaning to achieve a new satisfying scheme. A detailed study of the drawings suggests that there are four important shifts and stages in the evolution of the court idea and 
Figure 4 A variation where path circles around the court. (C) James Stirling/Michael Wilford Archive, Centre Canadien d'Architecture/Canadian Centre for Architecture, Montréal)



its relation to the path: first when the idea of a court emerged, second when its form was decided as a circular court, third when the path and court were integrated, and fourth when the public space defined by the court became a positive defining space.

\section{Dynamics of generic abstraction}

During the design process, communication among the team members evolved mainly through sketches and diagrams (Schaad). Wilford, Stirling's office partner, describes this collaboration in terms of successive stages. First, the brief or the program document was placed on the desk of everyone involved in the design. From then on, Wilford reports 'a wide ranging diagrammatic exercise [was] carried out to establish all possible ways of configuring the building' (Wilford, 1996, p. 14). The members of the team would create photocopies of their sketches and Stirling would take these as the basis of his own sketches. Stirling would work on these alternative sketches to select, edit, alter, and add (Girouard, 1998). He would do this by 'taking the A4 photocopied clip and
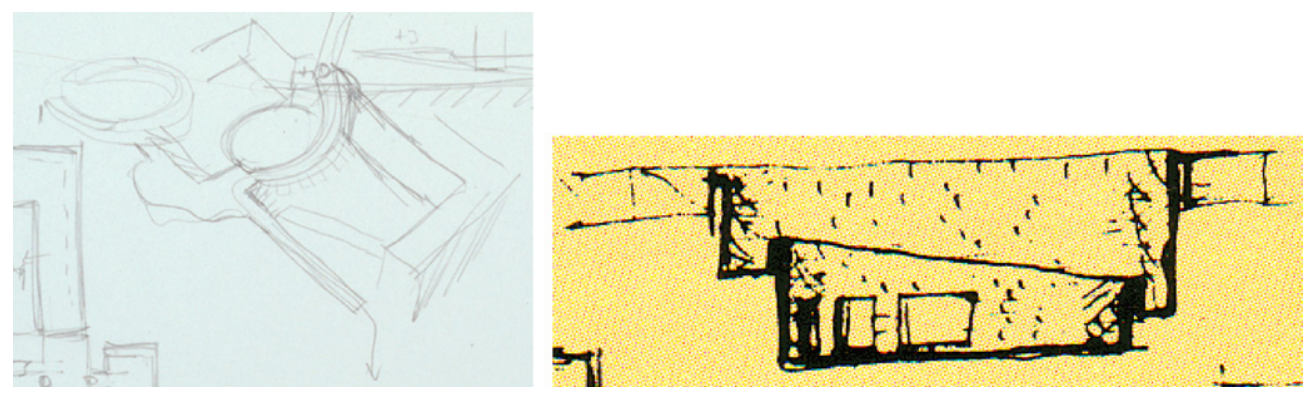

Figure 5 Two variations where path circles downwards. (@ James Stirling/Michael Wilford Archive, Centre Canadien d'Architecture/Canadian Centre for Architecture, Montréal) 

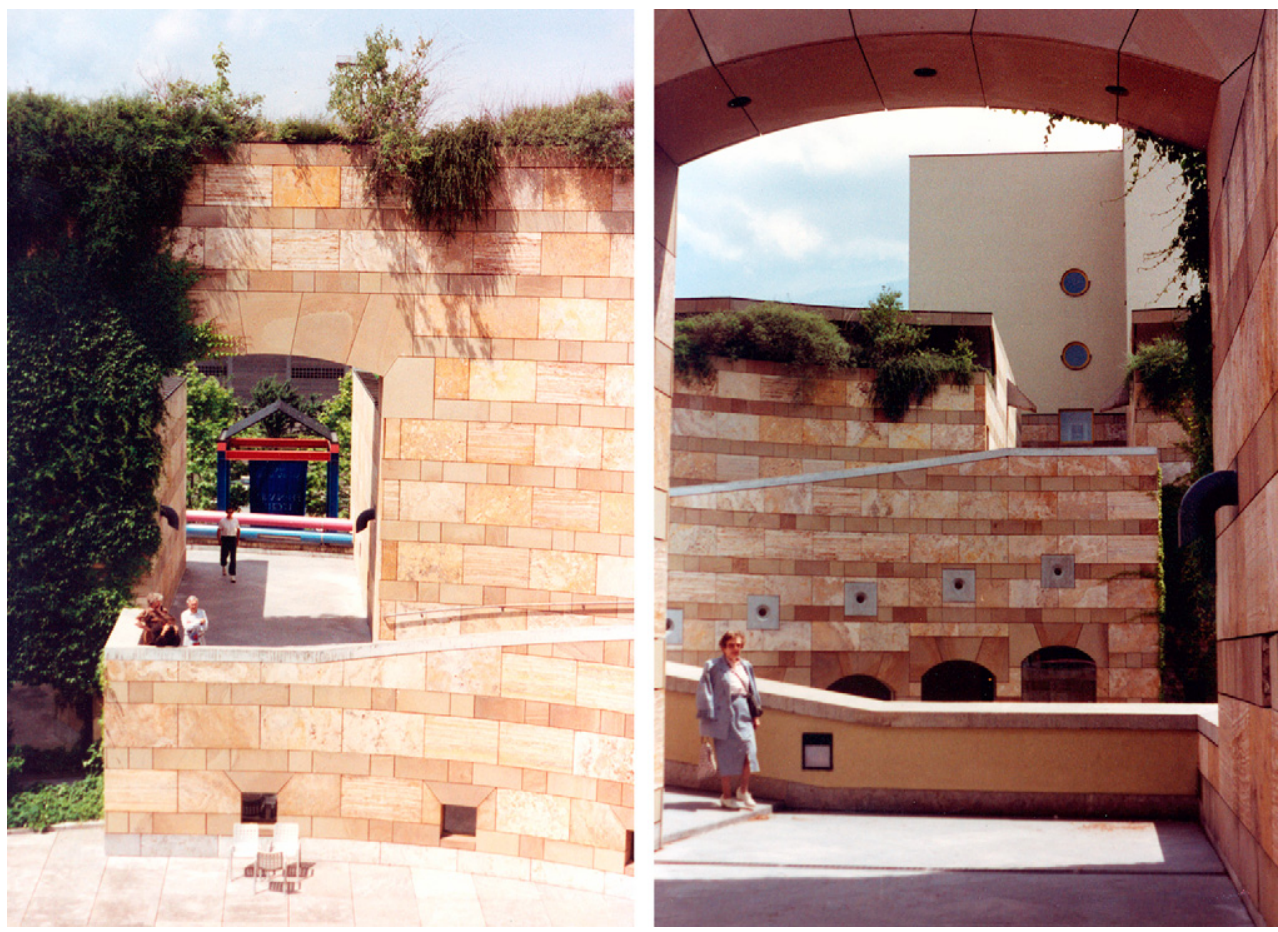

Figure 6 Views towards the entry of the court towards the lower terrace (Left) and towards the top of the ramp (Right)

putting an A4 tracing paper on top and doodling' (Girouard, 1998, p. 248). Wilford characterizes Stirling's manipulation of others' sketches as a process of simplification of the complexity of the design situation. Later, Wilford would describe his own role in the same way, as one which is similar to the role of a newspaper editor 'who receives copy from his journalists and then suggests how it might be altered or the emphasis changed' (Lawson, 2006, p. 250). The drawings were reduced to their basics and essentials, which Wilford describes as 'stripping away extraneous information [our emphasis]... by overlaying tracing paper on an under drawing and redrawing it, often many times, until the scope and detail are paired down as required' (Wilford, 1994, p. 5). According to Bevington, through this processes Stirling gained mastery which allowed him 'to pick on ideas (drawn) and mould them into the whole once a basic scheme had been determined.' He explains as follows:

'It was always 'one step at a time " with Stirling - a good diagrammatic scheme that resolved the functions of the brief, relationships etc. which would then be developed to produce a piece of architecture in its urban context.' (Bevington)

The strategy of simplifying the exploration by way of reducing the set of available design solutions was a conscious effort on the part of the designers. Wilford expresses this as follows: 
'Not big on words, he [Stirling] explored ideas in diagrammatic sketches. The office was a searching factory; it was not a pick-and-choose operation but an elaboration of an agreed-upon set of ideas, a sequence of sketches rather than 25 alternatives.

If you structure the process properly you don't have to concern yourself with extraneous matters or details until an appropriate time. You prioritize the issues under consideration and begin work with the fundamentals. This is a bare bones method of designing in which the brief is always distilled to a simple graphic representation [italics added] in order to establish connections between the spaces the building has to accommodate and the site on which they are to be situated - a diagrammatic comparison.' (Wilford, 1993, p. 57)

The sketches and diagrams from the design process are small, simple, and drawn on standard, small size sketching papers. Their simplified, abstract form makes them easier to study, to inspect, and to grasp the essentials and formulate them in generic conceptual diagrams. Furthermore, there is usually a set of sketches on a page making simultaneous comparisons more efficient. During the design process, abstraction followed a period of exploration of different variations of design themes. Variations consisted of explorations of the idea of a diagonal path and the idea of a sculpture court and they were developed exclusively by the junior designers. Both Bevington and Schaad report that the whole process they worked side-by-side and discussed and exchanged ideas constantly but they developed separate schemes and alternatives. Exploring variations, the team focused on detailing and comparing alternatives, whereas during the period of abstraction, alternatives were simplified and their details were removed until a generic integrative conceptual scheme was achieved, which in turn became an organizing principle to simplify exploration. It was Stirling who was deriving generic abstractions based on individual schemes of Bevington and Schaad. We now discuss three major instances of such generic abstraction.

\subsection{First generic abstraction}

In the first instance of generic abstraction, Stirling used abstraction to transfer architectural components from the Düsseldorf competition project (Figure 7a) to the Staatsgalerie project. In this early schematic plan drawing (Figure 7b), which belongs to a set of drawing schemes without a court, there is a generic scheme drawn in red pen. (For interpretation of the references to colour in figures, the reader is referred to the web version of this article.)

We know that the convention of the office was for only Stirling to use a red pen to edit and comment on the drawings of the other designers (Girouard, 1998; Wilford, 1994). In Figure 7b, we propose that Stirling abstracted the Düsseldorf scheme to its bare bones as a square and a path with a court, which made it easier for him to transfer only these generic elements and their 

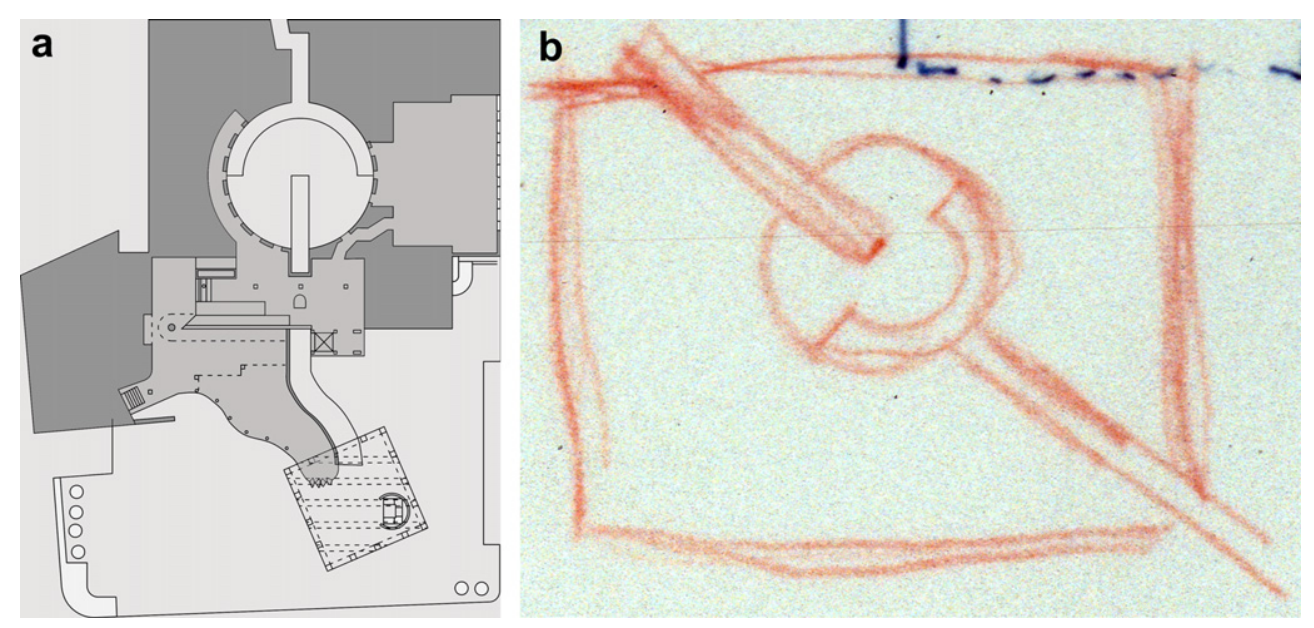

Figure 7 (a) Museum for North Rhine-Westphalia (Düsseldorf, 1975); (b) first generic abstraction (@ James Stirling/Michael Wilford Archive, Centre Canadien d'Architecture/Canadian Centre for Architecture, Montréal)

relationship to the Staatsgalerie competition project and adapt them to the new project.

\subsection{Second generic abstraction}

Among the early sketches of Staatsgalerie, there are several indicative of how the schemes are compared through re-sketching by superimposing papers or by tracing over the sketches. With one such drawing (Figure 8), the team configured a generic scheme regarding the nature of the path and the court.

In this drawing, the superimposed lines show three phases of abstraction on the idea of path: blue dashed lines, a red dashed line, and a gray diagonal line with a circle at the center. Here, two parallel dashed blue lines at the

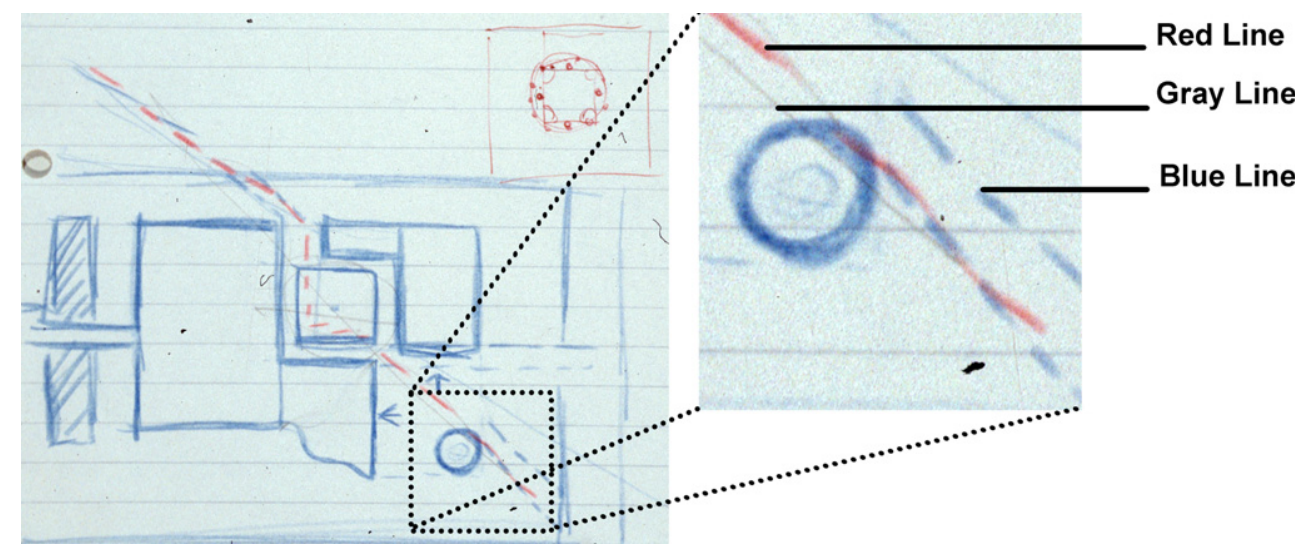

Figure 8 The second generic abstraction with the three levels of abstraction. (๔) James Stirling/Michael Wilford Archive, Centre Canadien d'Architecture/Canadian Centre for Architecture, Montréal) 


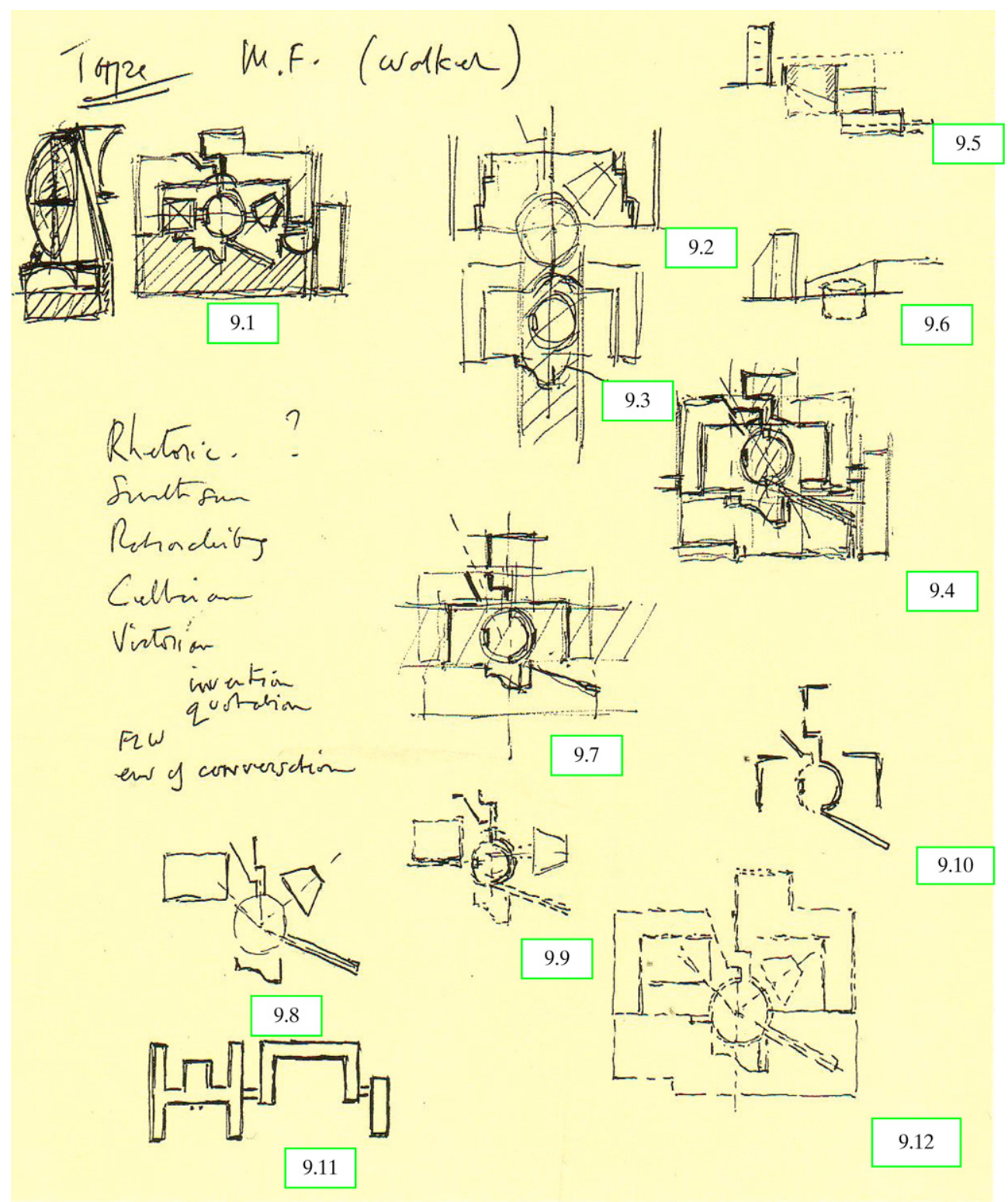

Figure 9 Progressive abstraction in Stirling's diagrams (published in Muirhead, 1986, p. 51)

entrance of the site and at the exit of the site literally correspond to a path with a specific width. The red dashed line superimposed on the blue line, however, is more abstract and represents the movement and not a particular path. This line abstracts the path to a circulation line, representing the trajectory of the movement and the turns along this trajectory. The third superimposed line, i.e., barely visible gray line crossing the circle, advances abstraction one step further. Here the indication is not of width or trajectory, but rather it denotes 
the architectural notion of an abstract circulation axis passing through the building.

The difference in the colors supports the claim that the abstraction evolved in three phases from path to movement to axis. Again, what is significant is the process of abstraction which enabled Stirling to think in terms of the generic issues concerning the path and its relation to the court rather than the specific physical properties of the design. Abstraction helped Stirling in thinking of the path in terms of a linear movement and of the court in terms of a central space located along the linear movement.

\subsection{Third generic abstraction}

A set of drawings by Stirling (Figure 9), illustrates the processes of abstraction through which Stirling conceived of an integrated generic scheme. The set starts with a plan drawing showing the configuration of the lecture hall, temporary exhibition space, and the court (Figure 9-9.1). They are all lined up on a linear axis. In two partial plan drawings, Stirling studied first the alignment of the court in relation to the museum block. The court is moved up and down within a vertical band (Figure 9-9.2, 9.3).

In the second complete plan drawing (Figure 9-9.4), Stirling introduced an abstract diagonal axial line representative of the public path going through the center of the sculpture court. This shows an effort to integrate the path and the court. In two small sections, Stirling sketched how the integration would work between the different levels of the upper terrace, the courtyard floor, and the lower terrace (Figure 9-9.5, 9.6).

In the third complete plan drawing (Figure 9-9.7), the diagonal axial line becomes a dashed line, which intersects with a vertical axial line. Here, the path and the court are defined according to an integrated set of axial lines. The vertical axial lines determine the positioning of the court while the horizontal band indicates the horizontal positioning of the court. Another important feature of this drawing is the differentiation of line thickness for different areas of the building complex. The interior contour lines of the building are thickened as opposed to the outer contour lines. This marks an emphasis on the in-between space defined by the building blocks.

In the following three partial plan drawings, Stirling studied this in-between space (Figure 9-9.8, 9.9 through 9.10). In the third drawing of this series (Figure 9-9.10), Stirling studied only the upper terrace floor of the scheme. Here, the void, composed of terraces and the courtyard, becomes both a constitutive element of the scheme and also the core of the composition. Goldschmidt and Klevitsky (2004) arrived at a similar conclusion through studying Stirling's three museum competitions. In each one of the projects, they illustrate how Stirling managed to turn a void into a major element of 
the scheme. This indicates how the central court became a focal area in the overall scheme when compared to the first plan drawing of this set in which the court is only one of the three equal spatial components of the scheme. Until now, each drawing furthers the abstraction process. In the last drawing, Stirling made a final complete drawing that is a re-configured arrangement of the interior spaces (Figure 9-9.12). Over the course of creating the drawings in the set, Stirling proceeded from a relatively detailed drawing to more and more abstract drawings and finally to a re-configured detailed scheme. The abstractive processes enabled Stirling to distill the detailed scheme to its basics, which in turn led to his reconfiguration of the overall composition of the path, the sculpture court, and the major spatial components.

Generic abstractions were produced by using conventional abstract diagrammatic features, such as axial lines, hatched vertical or horizontal zones, and differentiation of line thicknesses. All the other drawings in the entire collection of the archive, with the exception of the diagram from the second instance of abstraction, lack such abstract diagrammatic features.

In the first instance of abstraction, Stirling introduced the notion of a central court in relation to a path. In the second, he studied how the path and the court could relate to each other. In the third, he qualified this relation by devising a path that would accommodate both those who are passing through the building and those who would like to pause.

\section{Discussion}

Stirling's design team made use of generic abstraction deliberately in their exploration. The designers devised procedures that would facilitate the abstraction process. The sketches were small so that they could easily be inspected by the eye (Wilford, 1994), which Lawson (2004) reports is common among some major designers he studied in detail. The sketches from Staatsgalerie were on standard, often semi-transparent sketch paper, to facilitate comparison through superimposition. Different types of lines in the renderings had specific meanings within the group, making communication efficient and the drawings less ambiguous. The basic line types consisted of dashed lines indicating circulation; continuous lines indicating spatial boundaries; axial lines, for spatial configuration; and thicker lines for emphasizing spaces. The office also limited the color range in their drawings. Black ink was assigned to all designers, except the senior designer, who used red ink, especially when trying to reduce sketches to their 'barebones'. All of the above indicate a deliberate effort to facilitate abstraction and exploration in a collaborative design process.

The notion of a cognitive system is helpful for capturing the structured collaboration during the Staatsgalerie project (Hutchins, 1995). The design progressed in a distributed fashion, involving the generation, manipulation, and 
propagation of representational states across media. Within the cognitive system junior and senior designers, as well as representations in the form of sketches and diagrams, performed distinct functions which together constitute the design process. The senior designer was in charge of leading the team by providing direction and integrating the various ideas of junior designers with mostly diagrammatic abstractions. The syntax and semantics of representations were relatively unambiguous to the members of the design team (cf. Goel, 1995). Axial lines, hatching, and dashed lines designated specific abstractions. When these were in red they specified a clear direction for the design exploration by the senior designer. While sketches were produced exclusively by the junior designers and were representative of specific design variations, the abstractions through diagrams were used only by the senior designer to provide a lead to the design process and to sum up what the junior designers were working on. This assures that in the design process there is some flexibility in exploring different variations at first, followed by periods of summation which would delimit the boundaries of the exploration space. This suggests a design process which evolves in alternating phases of expanding the exploration space and of bringing focus to the exploration.

The Staatsgalerie design team explored a vast, but related, number of variations in the initial phases of design, yet this was neither an exhaustive search nor a linear search. It did not need to be exhaustive because the variations generated by the junior designers were occasionally summarized into generic schemes by Stirling, and they generated further, related variations. The fact that the exploration was neither exhaustive nor linear was ensured in the cognitive system in which the senior designer defined the limits of the exploration space through generic abstractions and the junior designers considered different variations within those limits.

The exploration was not linear because the team considered several variations more or less at the same time, which facilitated comparisons of different schemes. Some sets of sketches for the Staatsgalerie project, for instance, show a vast number of variations studied together. Others, which show a detailed rendering of one variation, have smaller sketches accompanying them, suggesting that the designers were considering related variations simultaneously and sometimes going back to a previous variation. In other sketches, drawings and layers are superimposed again suggesting an iterative rather than linear exploration. The designers considered several different schemes, compared them to each other, and sometimes jumped back and forth between schemes.

When we look at the nature and progress of the exploration in the design process, we see that the cognitive system is set up so as to have alternating episodes of conceptualization and focus on design solutions. The beginning of design in the Staatsgalerie design project was marked by the identification of two 
precedents and significant design elements, the latter in response to the challenge presented in the competition brief. This indicates an exploration starting in the solution space and not in the problem space, in contradiction to what Goel and Pirolli (1992) suggested in their descriptive model of design. Goel and Pirolli claimed that the early phases of design are dedicated to problem structuring rather than problem solution; however, in the case of the Staatsgalerie, the initial phase of design was mostly dedicated to generating specific design schemes comprising variations of a few design elements. The two precedents that were identified highlighted a series of design features relevant to the issues discussed in the design challenge. However, at this stage the designers did not restructure the problem definition or formulate a single conceptualization to restructure their problem representation so that the presumably contradictory objectives of their design tasks would be resolved.

An emphasis on solution in the initial phases of design has also been well documented in the literature of design cognition. Lawson (1979) compared science students to architecture students and found that architecture students began with solutions immediately. Lloyd and Scott (1994) showed that expert designers, when they have enough experience in a particular design task, start with solutions rather than with problem definition.

The Staatsgalerie project is a clear illustration of a group of designers with substantial prior experience in their particular design task starting the design process with a solution scheme. When starting the project, Stirling stated that this project was going to be phase 2 of the Düsseldorf Museum project. The design task of the Staatsgalerie was familiar to the design team. Three members of the Düsseldorf project constituted the core team for the Staatsgalerie. The same team had worked with others on the Wallraf-Richartz Museum project two years before the Staatsgalerie project began. Furthermore, there were enough overlaps between the Düsseldorf and Stuttgart projects, e.g., program, client, context, scale, and a relatively short time gap between the two projects (two years), that the office did not have to go through a thorough conceptual exploration process and did not come up with a single conceptualization identifying the salient features of their design scheme.

On different occasions, however, especially when Stirling participated in the design, the nature of the exploration changed significantly. When Stirling was involved in the design he was mainly in charge of identifying the underlying ideas of the variations generated by the junior designers, looking for generic features that were shared by them, and establishing consistent relationships among them. It was during this process that new ideas were formulated, previous ideas were modified and, above all, the contradictory objectives of the design challenge were studied. This process is best characterized as creating generic abstractions of specific variations. 
The restructuring of the design problem in the design of the Staatsgalerie through generic abstraction brought each time a new and wider perspective to the design, which could be described as a lateral transformation following Goel's definition (1995). In the sense that generic abstractions are also rerepresentations they are similar to re-representation of problems in insight problems in order to break an impasse (Akin \& Akin, 1996; Knoblich, Ohlsson, Haider, \& Rhenius, 1999). The difference between moments of illumination in insight problems and the shift in problem representation in the Staatsgalerie design task is that the former is a sudden and momentary realization of a new dimension of the problem whereas in the latter the shift occurred through a structured process, herein called generic abstraction. Abstracting from the perceptual features of the conceptual diagram allowed Stirling to isolate only the necessary, basics elements. Once the basics were isolated, Stirling was better able to manipulate the elements to search for a meaningful relationship between them.

The series of shifts in design conception that we illustrated earlier are difficult to account for as serendipitous discoveries. Although we cannot detail more cases here, from our investigations this case is not an atypical instance of discovery in design (Dogan \& Nersessian, 2005). On the one hand, the Staatsgalerie case study aligns with accounts of design cognition that emphasize the centrality of sketches as the primary architectural representations in the process of discovery (Goel, 1995; Goldschmidt, 1991; Schön, 1992). On the other hand, it provides an alternative to views that single out the serendipity of discovery processes in design and the role of unconstrained sketching while ignoring the more structured processes of discovery that are also evident in design. Some researchers in design studies emphasize the view that designers often stumble upon new things while manipulating sketches, and benefit from them opportunistically (Cross, 2001; Cross \& Cross, 1995). This no doubt happens with both expert and novice designers; however this fosters a view of designers as frantically doodling in hopes of suddenly discovering satisfying schemes. Our analysis highlights a process in which discoveries do not stem from reinterpretations of already existing visual marks in an unexpected manner (Suwa et al., 2000) but stem from deliberate efforts to attain insight by means of abstraction via drawing new generic diagrams representing a class of design schemes.

As we have noted, studies of scientific discovery, too, have shown the importance of generic abstraction as a means of structured exploration leading to creative outcomes. Nersessian $(1999,2008)$ proposed that generic abstraction facilitates building mental models that embody commonalities across seemingly dissimilar domains in scientific reasoning processes such that inferences derived from the specific representations of models used in an exploration can be understood as applying to members of classes of phenomena. Similarly, in 
design it is possible to infer or derive multiple variations from a specific representation of a generic abstraction that has wider applicability.

Further, research in other areas of cognitive science lends support to our argument. Gattis and Holyoak's (1996) research on graphs, e.g., provides one explanation for why abstraction could be important. They compared the effectiveness of graphs that have a higher pictorial correspondence with what is represented to graphs that preserve the correspondence at a more abstract level. Their results suggest that abstract representations of conceptually important features have significant advantages for making inferences. In Stirling's second case of abstraction (Figure 8), for instance, the progression from a relatively more realistic representation of the path to a more abstract representation of the idea of movement indicates an effort to emphasize the conceptually important features and align the attention of the design team on these.

An additional reason for the productivity of gradual abstraction of design schemes might relate to the ease of manipulation of the perceptual features of diagrams when they are simplified. In the Staatsgalerie, once design ideas were abstracted and associated with perceptual features of diagrams, manipulation of their perceptual features could facilitate manipulating features of a corresponding mental model, enabling the designers to simulate potential pathways. Through step-by-step abstraction Stirling can be interpreted as not only reducing the details of the drawings but also simulating a series of complex connected spaces. This point is clearer in diagrams from third case of abstraction. In this series Stirling abstracted elements of the design one at a time, as if he were simulating each element of the scheme at each stage of abstraction. Such piecemeal abstraction is similar to the notion of piecemeal animation of diagrams of complex mechanical systems, in which only parts of the system are animated at any given time (Hegarty, 1995). Narayanan, Suwa, and Motoda (1995) and Qin and Simon (1995) also suggested that piecemeal manipulation of diagrams facilitate making inferences from complex mental models.

Finally, Greeno (1989) offers direction for developing a theoretical basis for understanding how manipulating diagrams can serve to facilitate transformations of mental models. He introduced a view of semantics in which structured systems of symbolic notations are mapped to structured systems of objects and events, and suggested that inferences are possible through manipulation of either system. On his account, mental models are structured systems of symbolic notations and correspond to structured systems of objects and events in the form of physical models. Any transformation in the external representation, therefore, can create a corresponding transformation in the mental model. The third abstraction in the Stirling case provides evidence that through manipulating the physical features of the diagram Stirling altered his corresponding conceptualization. Reasoning via generic abstraction enabled the designer 
to think of the central court both as a focal and stopping point along a trajectory of movement.

\section{Conclusion}

The design of the Staatsgalerie was a coordinated effort among a team of designers. Ideas were exchanged through simplifying and abstracting representations through re-sketching. These processes enabled the design team members to identify the salient features of their schemes and formulate them in generic diagrammatic representations. Generic abstraction by means of diagrams facilitated aligning and propagating design commitments in the distributed cognitive system.

The case illustrates a design process which evolved not through serendipitous discoveries in sketches but through generic abstractions and variations derived from these abstractions. We identified three such instances of generic abstraction in the case study: the first when the designer transferred the main generic components of an earlier project, the second and third when the senior designer abstracted the main design issues from variations produced by the junior designers. The generic design abstractions defined a family of design schemes which helped the designers remain committed to a set of designs. The variations considered could in turn be compared to each other for final decision making. Finally, the generic abstractions in the form of diagrams potentially helped the designers to mentally simulate different spatial components, especially the trajectories of possible movements through the physical space, which lead to the generation of a novel design conceptualization.

\section{Acknowledgements}

We would like to thank Craig Zimring for his insightful contributions during the research, the staff of Canadian Centre for Architecture for their assistance during the archival studies and in acquiring the permissions to reprint the archival material, and finally Yenal Akgün for his help with the figures.

\section{Appendix. Questions sent to Russell Bevington and Ulrich Schaad}

1. When was the competition announced?

2. When did the office receive the invitation?

3. When did the office receive the brief?

4. Was the brief in German or in English?

5. Did anybody from the office visit the site prior to the design? If yes who and when?

6. When did James Stirling first go to Stuttgart?

7. When was he in the States to teach at Yale University?

8. When did he come back from Yale University?

9. How far did you advance in the design? 
10. How long did you work together afterwards?

11. When was the entry sent to Stuttgart?

12. Were you in close collaboration with Bevington/Schaad? Or were you working separately on independent schemes?

13. How did you collaborate?

14. How did you present your ideas to James Stirling?

15. How did he use those ideas in the final design?

16. What was the role of sketches and diagrams throughout the exploration phase? What were their roles in communication among yourselves?

17. The conceptual sketch which was first published on the cover of the $9 / 10$ issue of Architectural Design magazine is based on an earlier thumbnail sketch [see Figure 9]. When were those thumbnail sketches drawn? When was the cover sketch drawn?

18. Was it used also as such during the design phase as representative of the final solution to the search for the path and its relation to the courtyard?

19. What was the role of the conceptual sketch during the design process?

20. Who did the thumbnail sketches and the cover sketch?

21. Were the additions in the cover sketch later additions? Were they added just for publication?

22. In the first scheme the courtyard idea was not there. How and when did it emerge?

23. There are several variations of the public path starting from earlier ones which are literally diagonally crossing the site, to meandering paths, to paths that are more incorporated into the scheme with the courtyard. How did the idea of path evolve?

24. What was the influence of the brief on the design, especially regarding the idea of path? How did it shape the design?

25. How did the design of Düsseldorf and Cologne influence the design?

26. When were the results announced?

27. What were the changes to the scheme after the announcements of the results?

\section{References}

Akin, O., \& Akin, C. (1996). Frames of reference in architectural design: analysing the hyperacclamation (A-h-a-!). Design Studies, 17(4), 341-361.

Baker, G. (1992). Stuttgart promenade. Architectural Review, 191(1150), 76-78.

Blundell-Jones, P. (1985). Man or superman? Architects' Journal, 181(6), 44-55.

Colquhoun, A. (1984). Democratic monument: Neue Staatsgalerie, Stuttgart. Architectural Review, 176(1054), 19-47.

Cross, N. (2001). Design cognition: results from protocols. In C. M. Eastman, W. M. McCracken, \& W. C. Newstetter (Eds.), Design knowing and learning: Cognition in design education (pp. 79-103). Amsterdam; New York: Elsevier Science B.V.

Cross, N., \& Cross, A. C. (1995). Observations of teamwork and social processes in design. Design Studies, 16, 143-170. 
Darden, L. (1991). Theory change in science: Strategies from mendelian genetics. New York: Oxford University Press.

Dogan, F., \& Nersessian, N. J. (2005). Design problem solving with conceptual diagrams. In B. G. Bara, L. Barsalou, \& M. Bucciarelli (Eds.), 2005 Cognitive science society conference, stresa, Italy July 21-23 2005: Proceedings (pp. 600-605). Lawrence Erlbaum Associates.

Dogan, F., \& Zimring, C. M. (2002). Interaction of programming and design: the first unitarian congregation of Rochester and Louis I. Kahn. Journal of Architectural Education, 56(1), 47-56.

Filler, M. (1984). Cultural centering: Neue Staatsgalerie and chamber theater, Stuttgart, West Germany. Architectural Record, 172(10), 140-149.

Fraser, I., \& Henmi, R. (1994). Envisioning architecture: An analysis of drawing. New York: Van Nostrand Reinhold.

Gattis, M., \& Holyoak, K. J. (1996). Mapping conceptual to spatial relations in visual reasoning. Journal of Experimental Psychology/Learning, Memory \& Cognition, 22(1), 231-240.

Giere, R. N. (1988). Explaining science: A cognitive approach. Chicago: University of Chicago Press.

Giere, R. N. (Ed.). (1992), Cognitive models of science, Vol. xv. Minneapolis, MN: University of Minnesota.

Girouard, M. (1998). Big jim: The life and work of James Stirling. London: Chatto \& Windus.

Goel, V. (1995). Sketches of thought. Cambridge, MA, US: MIT Press.

Goel, V., \& Pirolli, P. (1992). The structure of design problem spaces. Cognitive Science, 16(3), 395-429.

Goldschmidt, G. (1991). The dialectics of sketching. Creativity Research Journal, $4(2), 123-143$.

Goldschmidt, G., \& Klevitsky, E. (2004). Graphic representation as reconstructive memory: Stirling's German museum projects. In G. Goldschmidt, \& W. L. Porter (Eds.), Design representation (pp. 37-61). London; New York: Springer.

Gooding, D. (1990). Experiment and the making of meaning: Human agency in scientific observation and experiment. Dordrecht: Kluwer.

Greeno, J. G. (1989). Situations, mental models, and generative knowledge. In D. Klahr, \& K. Kotovsky (Eds.), Complex information processing: The impact of Herbert A. Simon (pp. 285-318). Hillsdale, NJ: Erlbaum.

Hegarty, M. (1995). Mental animation: inferring motion from static displays of mechanical systems. In B. Chandrasekaran, J. Glasgow, \& N. H. Narayanan (Eds.), Diagrammatic reasoning: Cognitive and computational perspectives (pp. 535-575). Menlo Park, CA/Cambridge, MA: AAAI Press/MIT Press.

Holmes, F. L. (1985). Lavoisier and the chemistry of life: An exploration of scientific creativity. Madison: University of Wisconsin Press.

Hutchins, E. (1995). Cognition in the wild. Cambridge, MA, US: MIT Press.

Kahn, L. I. (1960). On form and design. Journal of Architectural Education, 15(3), 62-65.

Knoblich, G., Ohlsson, S., Haider, H., \& Rhenius, D. (1999). Constraint relaxation and chunk decomposition in insight problem solving. Journal of Experimental Psychology: Learning, Memory \& Cognition, 25(6), $1534-1555$.

Lawson, B. (1979). Cognitive strategies in architectural design. Ergonomics, 22(1), $59-68$.

Lawson, B. (1994). Design in mind butterworth architecture. Oxford, Boston. 
Lawson, B. (2004). What designers know. Boston, MA: Elsevier/Architectural Press.

Lawson, B. (2006). How Designers Think: The Design Process Demystified. Amsterdam, London: Architectural Press.

Lemos, P. (1985). Stuttgart: a populist palace of art. Art News, 84(2), 125-126.

Lloyd, P., \& Scott, P. (1994). Discovering the design problem. Design Studies, 15(2), 125-140.

Maher, L., \& Tang, H.-H. (2003). Co-evolution as a computational and cognitive model of design. Research in Engineering Design, 14(1), 47-64.

Muirhead, T. (1986). New Staatsgalerie and workshop theatre, Stuttgart, 1977-84. Architecture and Urbanism, (11), 23-54.

Narayanan, N. H., Suwa, M., \& Motoda, H. (1995). Hypothesizing behaviors from device diagrams. In B. Chandrasekaran, J. Glasgow, \& N. H. Narayanan (Eds.), Diagrammatic reasoning: Cognitive and computational perspectives (pp. 501-534). Menlo Park, CA/Cambridge, MA, US: AAAI Press/MIT Press.

Nersessian, N. J. (1992). How do scientists think? Capturing the dynamics of conceptual change in science. In R. N. Giere (Ed.), Cognitive models of science (pp. 3-44). Minneapolis, MN: University of Minnesota.

Nersessian, N. J. (1995). Opening the black box: cognitive science and history of science. Osiris, 10, 194-211.

Nersessian, N. J. (1999). Model-based reasoning in conceptual change. In L. Magnani, N. J. Nersessian, \& P. Thagard (Eds.), Model-based reasoning in scientific discovery (pp. 5-22). New York: Kluwer Academic/Plenum Publishers.

Nersessian, N. J. (2002). Abstraction via generic modeling in concept formation in science. Mind \& Society, 3(1), 129-154.

Nersessian, N. J. (2008). Creating scientific concepts. Cambridge, MA, US: MIT Press.

Pélissier, A., \& Stirling, J. F. (1986). James Stirling, sa conception du musée. Techniques et Architecture, 368(Oct-Nov), 127-129, 147.

Qin, Y., \& Simon, H. (1995). Imagery and mental models in problem solving. In B. Chandrasekaran, J. Glasgow, \& N. H. Narayanan (Eds.), Diagrammatic reasoning: Cognitive and computational perspectives (pp. 403-434). Menlo Park, CA/Cambridge, MA, US: AAAI Press/MIT Press.

Rodiek, T., \& Stirling, J. F. (1984). James Stirling: Die neue Staatsgalerie Stuttgart G. Stuttgart: Hatje.

Schön, D. (1992). Designing as reflective conversation with the materials of a design situation. Research in Engineering Design, 3(3), 131-147.

Stirling, J. F. (1980). The monumental tradition. Perspecta, (16), 32-50.

Stirling, J. F. (1984). Die Neue Staatsgalerie, Stuttgart. Domus, (651), 2-15.

Stirling, J. F., \& Wilford, M. (1984). James Stirling, Michael Wilford and Assoc.: Staatsgalerie extension and New Chamber Theatre, Stuttgart, West Germany, design: 1977-80, completion: 1984. GA Document, (11), 8-33.

Suwa, M., Gero, J., \& Purcell, T. (2000). Unexpected discoveries and S-invention of design requirements: important vehicles for a design process. Design Studies, 21(6), 539-567.

Thagard, P. (2002). Curing cancer? Patrick Lee's path to the reovirus treatment. International Studies in the Philosophy of Science, 16(1), 79-93.

Waterfield, G. (1987). James Stirling's masterpiece: the Neue Staatsgalerie Stuttgart. Apollo, 126(305), 41-43.

Werner, F. (1984). The new Acropolis of Stuttgart: the Neue Staatsgalerie by James Stirling and Michael Wilford. Lotus International, (43), 22-47. 
Wild, D. (1977). British architecture. Architectural Design, 47(9).

Wilford, M. (1993). Michael Wilford: a conversation in London. (interview). Any, 1(2), 56-61.

Wilford, M. (1994). Introduction, in James Stirling Michael Wilford and Associates. In M. Wilford, \& T. Muirhead (Eds.), James Stirling, Michael Wilford, and Associates: Buildings \& projects, 1975-1992. London: Thames \& Hudson.

Wilford, M. (1996). An evolving design philosophy and working method. In M. Wilford, \& Royal Institute of British Architects. (Eds.), Wilford, Stirling, Wilford (pp. 10-15). London: Michael Wilford \& Partners.

Zhang, J. (1997). The nature of external representations in problem solving. Cognitive Science Journal, 21(2), 179-217.

Zhang, J., \& Norman, D. A. (1994). Representations in distributed cognitive tasks. Cognitive Science Journal, 18(1), 87-122. 